\title{
Changes in the T-lymphocyte immune functions of patients with cervical cancer after surgery and their clinical significance.
}

\author{
Li-Bo Li ${ }^{1 \#, ~ Y i ~ Y a n g ~}{ }^{1 \#, ~ Y o n g ~ L i ~}{ }^{1}$, Han-Qun Zhang ${ }^{1}$, Zhao-Peng Zheng ${ }^{1}$, Yan-Ping Chen ${ }^{1}$, Ying-Jie Nie ${ }^{2 *}$ \\ ${ }^{1}$ Department of Oncology, People's Hospital of Guizhou Province, Guiyang, Guizhou, PR China \\ ${ }^{2}$ Department of Scientific Research and Education, People's Hospital of Guizhou Province, Guiyang, Guizhou, PR \\ China
}

\#These authors contributed equally

\begin{abstract}
Objective: This study aimed to discuss changes in the T-lymphocyte immune functions of patients with cervical cancer after surgery and their clinical significance.

Methods: A total of 80 patients with cervical cancer who had undergone surgical treatment in our hospital from January 2014 to July 2017 were selected as the observation group. Additionally, 50 healthy women volunteers in the same time period were considered as the control group. T-lymphocyte-secreted cytokines and T-lymphocyte immune function indices were examined before and after surgery of all respondents. Detection results of the two groups before and after surgery were compared. The observation group was further divided into postoperative infection-free and postoperative infection groups according to the occurrence of postoperative infection. The T-lymphocyte-secreted cytokines and T-lymphocyte immune function indices of these two groups were compared.

Results: Interleukin (IL)-2, Tumor Necrosis Factor- $\alpha$ (TNF- $\alpha$ ), Interferon- $\gamma($ IFN- $\gamma)$, IL-2+CD4 ${ }^{+}$, TNF- $\alpha$ $+\mathrm{CD4}^{+}$, and IFN $\gamma+\mathrm{CD4}^{+}$levels of the observation group were lower than those of the control group $(\mathbf{P}<0.05)$. According to postoperative detection results, IL-2, TNF- $\alpha$, IFN- $\gamma$, IL-2+CD4+, TNF- $\alpha+\mathrm{CD}^{+}$, and IFN $-\gamma+\mathrm{CD4}^{+}$of the observation group increased sharply compared with those before surgery $(\mathbf{P}<0.05)$. IL-2, TNF- $\alpha$, IFN- $\gamma$, IL-2+CD4+, TNF- $\alpha+\mathrm{CD4}+$, and IFN- $\gamma+\mathrm{CD} 4+$ of the observation group after surgery are significantly higher than those of the control group $(P<0.05)$. Different indices of the postoperative infection group were higher than those of the postoperative infection-free group $(P<0.05)$. Conclusions: The T-lymphocyte immune functions of patients with cervical cancer recovered after surgery, and the immunity of the postoperative infection group was further enhanced.
\end{abstract}

Keywords: Cervical cancer, Infection, T-lymphocyte, Immune function.

Accepted on November 30, 2017

\section{Introduction}

Surgery is the main clinical treatment of cervical cancer but often influences the immune functions of patients to some extent and may trigger postsurgical infection [1]. To date, no agreement has been achieved on whether surgery affects immune functions dominated by T-lymphocytes [2]. For this reason, 80 patients with cervical cancer who had undergone surgical treatment in our hospital from January 2014 to June 2017 and another 50 healthy women were selected as the research object. Clinical significance of T-lymphocyte immune functions to patients with postoperative infection was discussed.

\section{Information and Methods}

\section{Information}

A total of 80 patients with cervical cancer who had undergone surgical treatment in our hospital from January 2014 to June 2017 were selected as the observation group. Another 50 healthy woman volunteers who came for physical examination were also considered as the control group. The two groups were comparable in general information $(\mathrm{P}>0.05)$. Specifically, the observation group aged from 33 to $59(46.17 \pm 10.62)$ in average, whereas the control group aged from 31 to 58 (45.89 \pm 10.43 ) in average.

\section{Methods}

T-lymphocyte-secreted cytokines and T-lymphocyte immune function indices were examined before and after surgery of all 
respondents. Cubital vein blood $(6 \mathrm{ml})$ under the empty stomach was collected, and $2 \mathrm{ml}$ was placed in an anticoagulant tube. The blood was kept under $4^{\circ} \mathrm{C}$ for natural coagulation. Later, serum was extracted and kept in a refrigerator under $20^{\circ} \mathrm{C}$. Subsequently, $4 \mathrm{ml}$ was placed into the anticoagulant tube and then centrifuged for $10 \mathrm{~min}$ under $4^{\circ} \mathrm{C}$ at a rate of $2000 \mathrm{r} / \mathrm{min}$. Peripheral individual hemocytes were collected. Monoclonal anti-CD3 and anti-CD28 were applied as stimulus, and protein transport retardant was added. The mixture was incubated for $2 \mathrm{~h}$ in a $\mathrm{CO}_{2}$ incubator at $37^{\circ} \mathrm{C}$, followed by cellular staining. Interleukin (IL)-2, Tumor Necrosis Factor- $\alpha$ (TNF- $\alpha$ ), and Interferon- $\gamma$ (IFN- $\gamma$ ) levels were tested by enzyme-linked immunosorbent assay. $\mathrm{IL}-2+\mathrm{CD} 4^{+}, \mathrm{TNF}-\alpha+\mathrm{CD} 4^{+}$, and IFN $-\gamma+\mathrm{CD} 4^{+}$were tested by flow cytometry using fluorescein-labeled antibody $[3,4]$.

\section{Observation indices}

T-lymphocyte-secreted cytokines and T-lymphocyte immune function indices of the observation and control groups before and after surgery were detected and compared.
After surgery, the observation group was further divided into the postoperative infection-free and postoperative infection groups. T-lymphocyte-secreted cytokines and T-lymphocyte immune function indices of these two groups were compared.

\section{Statistical analysis}

Observation data were processed by SPSS19.0. The enumeration data were examined by $\chi^{2}$-test, and measurement data were examined by t-test. $\mathrm{P}<0.05$ indicates statistically significant difference.

\section{Results}

\section{Preoperative detection results of the observation and control groups}

According to detection results before surgery, IL-2, TNF- $\alpha$, IFN- $\gamma$, IL- $2+\mathrm{CD} 4^{+}$, TNF- $\alpha+\mathrm{CD} 4^{+}$, and IFN- $\gamma+\mathrm{CD} 4^{+}$of the observation group are significantly lower than those of the control group $(\mathrm{P}<0.05)$ (Table 1).

Table 1. Preoperative detection results of the observation and control groups $(\bar{x} \pm s)$.

\begin{tabular}{|c|c|c|c|c|c|c|}
\hline Groups & IL-2 (pg/ml) & TNF- $\alpha(p g / m l)$ & IFN-Y (pg/ml) & ${\mathrm{IL}-2+\mathrm{CD4}^{+}(\%)}$ & TNF- $\alpha+$ CD4 $^{+}(\%)$ & IFN-y+CD4 ${ }^{+}(\%)$ \\
\hline Control $(n=50)$ & $27.45 \pm 7.56$ & $15.59 \pm 6.28$ & $20.62 \pm 7.37$ & $1.62 \pm 0.38$ & $1.34 \pm 0.35$ & $1.29 \pm 0.43$ \\
\hline $\begin{array}{l}\text { Observation } \\
(n=80)\end{array}$ & $18.94 \pm 5.18$ & $9.27 \pm 3.75$ & $13.24 \pm 5.64$ & $1.25 \pm 0.21$ & $0.97 \pm 0.19$ & $0.85 \pm 0.24$ \\
\hline $\mathrm{t}$ & 7.614 & 7.190 & 6.439 & 7.146 & 7.803 & 7.485 \\
\hline$P$ & 0.000 & 0.000 & 0.000 & 0.000 & 0.000 & 0.000 \\
\hline
\end{tabular}

Table 2. Postoperative detection results of the observation and control groups $(\bar{x} \pm s)$.

\begin{tabular}{|c|c|c|c|c|c|c|}
\hline Groups & IL-2 (pg/ml) & TNF- $\alpha(p g / m l)$ & IFN-Y (pg/ml) & ${\mathrm{IL}-2+\mathrm{CD4}^{+}(\%)}$ & TNF- $\alpha+\mathrm{CD}^{+}(\%)$ & IFN-y+CD4 $4^{+}(\%)$ \\
\hline Control $(n=50)$ & $27.45 \pm 7.56$ & $15.59 \pm 6.28$ & $20.62 \pm 7.37$ & $1.62 \pm 0.38$ & $1.34 \pm 0.35$ & $1.29 \pm 0.43$ \\
\hline Observation $(n=80)$ & $34.98 \pm 7.15$ & $22.67 \pm 7.09$ & $28.45 \pm 7.89$ & $2.04 \pm 0.42$ & $1.75 \pm 0.41$ & $1.80 \pm 0.51$ \\
\hline $\mathrm{t}$ & 5.714 & 5.783 & 5.644 & 5.750 & 5.860 & 5.882 \\
\hline$P$ & 0.000 & 0.000 & 0.000 & 0.000 & 0.000 & 0.000 \\
\hline
\end{tabular}

\section{Postoperative detection results of the observation and control groups}

According to the detection results after surgery, IL-2, TNF- $\alpha$, IFN- $\gamma$, IL- $2+\mathrm{CD} 4^{+}$, TNF- $\alpha+\mathrm{CD} 4^{+}$, and IFN- $\gamma+\mathrm{CD} 4^{+}$of the observation group are higher than those of the control group $(\mathrm{P}<0.05)$ (Table 2).

\section{Detection results of the observation group before and after surgery}

After surgery, IL-2, TNF- $\alpha$, IFN- $\gamma$, IL- $2+C D 4^{+}$, TNF- $\alpha+C D 4^{+}$, and IFN $-\gamma+\mathrm{CD}^{+}$of the observation group are significantly higher compared with those before surgery $(\mathrm{P}<0.05)$ (Table 3$)$.

Table 3. Detection results of the observation group before and after surgery $(\bar{x} \pm s, n=80)$.

\begin{tabular}{|c|c|c|c|c|c|c|}
\hline Time & IL-2 (pg/ml) & TNF- $\alpha(p g / m l)$ & IFN-Y (pg/ml) & ${\mathrm{IL}-2+\mathrm{CD4}^{+}(\%)}$ & TNF- $\alpha+$ CD4 $^{+}(\%)$ & IFN- $-\gamma^{+\mathrm{CD}^{+}}{ }^{+}(\%)$ \\
\hline Before & $18.94 \pm 5.18$ & $9.27 \pm 3.75$ & $13.24 \pm 5.64$ & $1.25 \pm 0.21$ & $0.97 \pm 0.19$ & $0.85 \pm 0.24$ \\
\hline After & $34.98 \pm 7.15$ & $22.67 \pm 7.09$ & $28.45 \pm 7.89$ & $2.04 \pm 0.42$ & $1.75 \pm 0.41$ & $1.80 \pm 0.51$ \\
\hline
\end{tabular}




\begin{tabular}{llllllll}
\hline $\mathrm{t}$ & 16.249 & 14.943 & 14.027 & 15.048 & 15.439 & 15.075 \\
\hline $\mathrm{P}$ & 0.000 & 0.000 & 0.000 & 0.000 & 0.000 & 0.000 & \\
\hline
\end{tabular}

\section{Detection results of the postoperative infection-free and postoperative infection groups}

Among the 80 patients with cervical cancer, 23 cases had postoperative infection and 57 cases had not. IL-2, TNF- $\alpha$,
IFN- $\gamma$, IL- $2+\mathrm{CD} 4^{+}$, TNF- $\alpha+\mathrm{CD} 4^{+}$, and IFN- $\gamma+\mathrm{CD} 4^{+}$of the postoperative infection group are higher than those of the postoperative infection-free group $(\mathrm{P}<0.05)$ (Table 4$)$.

Table 4. Detection results of the postoperative infection-free and postoperative infection groups $(\bar{x} \pm s)$.

\begin{tabular}{|c|c|c|c|c|c|c|}
\hline Groups & IL-2 (pg/ml) & TNF- $\alpha(\mathrm{pg} / \mathrm{ml})$ & IFN-v (pg/ml) & IL-2+CD4 ${ }^{+}(\%)$ & TNF- $\alpha+C D 4^{+}(\%)$ & IFN-p+CD4 ${ }^{+}(\%)$ \\
\hline Infection ( $n=23$ ) & $38.24 \pm 6.27$ & $25.96 \pm 5.86$ & $32.59 \pm 7.25$ & $2.38 \pm 0.61$ & $2.17 \pm 0.72$ & $2.26 \pm 0.83$ \\
\hline No-infection $(n=57)$ & $32.05 \pm 4.83$ & $20.13 \pm 3.94$ & $25.31 \pm 5.72$ & $1.76 \pm 0.47$ & $1.38 \pm 0.53$ & $1.41 \pm 0.70$ \\
\hline $\mathrm{t}$ & 4.749 & 5.171 & 4.761 & 4.889 & 5.422 & 4.656 \\
\hline$P$ & 0.000 & 0.000 & 0.000 & 0.000 & 0.000 & 0.000 \\
\hline
\end{tabular}

\section{Discussion}

Cervical cancer is a very common malignant tumor in women [5]. Morbidity increases in recent years, and the age of onset is continuously becoming young. Morbidity of cervical cancer is only next to breast cancer among malignant tumor in women and becomes an important disease that threatens life safety of women $[6,7]$. Surgery is the main clinical treatment of cervical cancer. It can excise lesion of cervical cancer and realizes the goal of inhibiting tumor development. However, surgery causes infection risk after the procedure [8].

The immune system is an important system that maintains stability of internal environment in human bodies. The internal environmental stability often will be broken, and cytogenesis escapes upon the occurrence of mutation in bodies, thus further causing tumor lesion [9]. Under this circumstance, the immunity effect of antitumor can be developed as long as the immune system recognizes tumor cells effectively. Immune cells are the subject of antitumor immunity effect, and $\mathrm{T}$ lymphocyte is the main immune cells [10]. This study discovered that IL-2, TNF- $\alpha$, IFN- $\gamma$, IL- $2+C D 4^{+}$, TNF- $\alpha$ $+\mathrm{CD}^{+}$, and IFN- $\gamma+\mathrm{CD} 4^{+}$of the observation group are higher than those of the control group $(\mathrm{P}<0.05)$, indicating that $\mathrm{T}$ lymphocyte in peripheral individual hemocytes of patients with cervical cancer was reduced and the killing effect to mutant cells was weakened. Chemotasis phenomena even develop. Tlymphocyte cannot kill mutant cells, reflecting that $\mathrm{T}$ lymphocyte may reduce participation in tumor development. In this study, IL- 2 , TNF- $\alpha$, IFN- $\gamma$, IL- $2+\mathrm{CD} 4^{+}, \mathrm{TNF}-\alpha+\mathrm{CD} 4^{+}$, and IFN $-\gamma+\mathrm{CD}^{+}$of the observation group after surgery are significantly higher than those before surgery $(\mathrm{P}<0.05)$ and higher than those of the control group after surgery $(\mathrm{P}<0.05)$. This finding indicated that after surgery, T-lymphocyte immune cytokines begins to recover. The reason is mainly because tumor load after surgery is relieved and thereby weakens the inhibition effect of cell immunity accordingly.
T-lymphocyte can not only cause antitumor immunity but also can eliminate inflammatory infection. In this study, indices of the postoperative infection group are higher than those of the postoperative infection-free group $(\mathrm{P}<0.05)$, implying that infection might activate T-lymphocyte immune system in bodies and enhance the immune reaction.

\section{Conclusion}

T-lymphocyte-secreted cytokines and immune function are inhibited in bodies with cervical cancer due to tumor. Tlymphocyte-secreted cytokines and immune function indices are recovering gradually after surgery. Postoperative surgery can further enhance immune reaction of patients with cervical cancer.

\section{References}

1. Case AJ, Roessner CT, Tian J, Zimmerman MC. Mitochondrial superoxide signaling contributes to norepinephrine-mediated T-lymphocyte cytokine profiles. PLoS One 2016; 11: 0164609.

2. Niu S, Zhang M. Study on the effect of chemotherapy on physical status of patients with nonsmall-cell lung cancer. Biomed Res India 2017; 28: 2466-2470.

3. Guillou L, Babataheri A, Saitakis M, Bohineust A, Dogniaux S, Hivroz C, Barakat AI, Husson J. Tlymphocyte passive deformation is controlled by unfolding of membrane surface reservoirs. Mol Biol Cell 2016; 27: 3574-3582.

4. Woods K, Knights AJ, Anaka M, Schittenhelm RB, Purcell AW, Behren A, Cebon J. Mismatch in epitope specificities between IFN $\gamma$ inflamed and uninflamed conditions leads to escape from $\mathrm{T}$ lymphocyte killing in melanoma. J Immunother Cancer 2016; 4: 10.

5. Chen K, Liu JY, Lei L. Comparison of the inhibition behavior of benzbromarone on liver metabolic capability 


\section{significance}

between health people and patients with liver cancers. Lat Am J Pharm 2017; 36: 1030-1034.

6. Liu MW, Su MX, Zhang W, Zhang LM, Wang YH, Qian CY. Rhodiola rosea suppresses thymus T-lymphocyte apoptosis by downregulating tumor necrosis factor- $\alpha$ induced protein 8-like-2 in septic rats. Int J Mol Med 2015; 36: 386-398.

7. Javaid F, Javeed A, Ashraf M, Nazir J, Ghafoor A, Ur Rehman MH, Fatima SF, Razzaq S. In vivo modulation of cellular and humoral immune response by the administration of naproxen sodium in mice. Lat Am J Pharm 2016; 35: 877-883.

8. Bourgioti C, Chatoupis K, Moulopoulos LA. Current imaging strategies for the evaluation of uterine cervical cancer. World J Radiol 2016; 8: 342-354.
9. Rajkumar K, Swaminathan P. Optimized energy aware scheduling to minimize makespan in distributed systems. Biomed Res India 2017; 28: 2877-2883.

10. Zhang W, Hou T, Niu C, Song L, Zhang Y. B3GNT3 expression is a novel marker correlated with pelvic lymph node metastasis and poor clinical outcome in early-stage cervical cancer. PLoS One 2015; 10: 0144360.

\section{*Correspondence to}

Ying-Jie Nie

Department of Scientific Research and Education

People's Hospital of Guizhou Province

China 